\title{
Viabilidade econômica da produção da tilápia do Nilo como atividade secundária em propriedades rurais no Estado do Rio de Janeiro
}

Economic viability of Nile tilapia production as a secondary activity in rural properties in the State of Rio de Janeiro

Viabilidad económica de la producción de tilapia del Nilo como actividad secundaria en propiedades rurales del estado de Río de Janeiro

Recebido: 30/01/2021 | Revisado: 05/02/2021 | Aceito: 10/02/2021 | Publicado: 20/02/2021

Raphael Pereira Siqueira
ORCID: https://orcid.org/0000-0001-7300-4529
Universidade Federal Rural do Rio de Janeiro, Brasil
E-mail: raphaelsiqueiravet @ @mail.com
Silvia Conceição Reis Pereira Mello
ORCID: https://orcid.org/0000-0002-5537-3563
Fundação Instituto de Pesca do Estado do Rio de Janeiro, Brasil
Empresa de Pesquisa Agropecuária do Estado do Rio de Janeiro, Brasil
Fundação Instituto de Pesca do Estado do Rio de Janeiro, Brasil
E-mail: silviaqua @uol.com.br
Thiago Bernardes Fernandes Jorge
ORCID: https://orcid.org/0000- 0003-2178-4679
Universidade Federal Rural do Rio de Janeiro, Brasil
E-mail: thbernardes@yahoo.com.br
José Teixeira Seixas Filho
ORCID: https://orcid.org/0000- 0002-5021-1290
E-mail: seixasfilho @yahoo.com.br
Marcelo Maia Pereira
Fundação Instituto de Pesca do Estado Ro Rio de Janeiro, Brasil
ORCID: https://orcid.org/0000-0002-1898-2722
Eundação Instituto de Pesca do Estado do Rio de Janeiro, Brasil
E-mail: mmaiap2001@yahoo.com.br

\section{Resumo}

A piscicultura tem passado por sucessivas transformações, se consolidando como uma importante atividade no agronegócio nacional. Destaca-se principalmente a criação de tilápias, uma espécie exótica, que apresenta um pacote tecnológico definido. Contudo, pouca importância tem sido dada ao conhecimento do aspecto econômico desta atividade, identificando a composição do custo de produção e os principais parâmetros que influenciam na sua rentabilidade, principalmente os gastos com ração, que podem chegar a $80 \%$ do custo total de produção. O presente trabalho teve por objetivo analisar os custos e a viabilidade econômico-financeira na produção de tilápias do Nilo em diferentes sistemas de criação em propriedades no Estado do Rio de Janeiro, para tanto foram analisadas 10 propriedades de diferentes tamanhos, estruturas permitindo melhor compreensão da realidade econômica e zootécnica da piscicultura no Estado do Rio de Janeiro. O custo médio de produção foi de $\mathrm{R} \$ 4,51 / \mathrm{kg}$ de peixe vivo. A ração responsável por $66,21 \%$ dos custos de produção, seguida $11,49 \%$ para as despesas com mão de obra. O valor médio de Payback encontrado foi de 0,65 anos. Já o Valor Presente Líquido apresentou resultado médio de R $\$ 161.161,35$ a uma taxa mínima de atratividade de $10 \%$ a.a., durante 10 anos, com uma Taxa Interna de Retorno de 188\%. A partir dos resultados encontrados para análises de custos, índices zootécnicos e da viabilidade financeira das pisciculturas de criação de tilápia do Nilo na região Sul Fluminense verificou-se que é rentável a produção deste peixe pelos produtores estudados.

Palavras-chave: Custo; Piscicultura; Viabilidade econômica.

\footnotetext{
Abstract

Fish farming has undergone successive transformations, consolidating itself as an important activity in national agribusiness. The creation of tilapia, an exotic species, with a defined technological package stands out. However, little importance has been given to the knowledge of the economic aspect of this activity, identifying the composition of the production cost and the main parameters that influence its profitability, mainly the expenditure on feed, which
} 
can reach $80 \%$ of the total production cost. The present work aimed to analyze the costs and the economic-financial viability in the production of Nile tilapia in different rearing systems in properties in the State of Rio de Janeiro, for that purpose 10 properties of different sizes, structures allowing a better understanding were analyzed. the economic and zootechnical reality of fish farming in the State of Rio de Janeiro. The average production cost was $\mathrm{R} \$ 4.51 / \mathrm{kg}$ of live fish. Ration accounts for $66.21 \%$ of production costs, followed by $11.49 \%$ for labor costs. The average value of Payback found was 0.65 years. Net Present Value, on the other hand, presented an average result of R \$ 161,161.35 at a minimum attractiveness rate of $10 \%$ a.a., for 10 years, with an Internal Rate of Return of $188 \%$. From the results found for cost analysis, zootechnical indexes and the financial viability of Nile tilapia fish farms in the South Fluminense region, it was verified that the production of this fish by the studied producers is profitable.

Keywords: Cost; Fish farming; Economic viability.

\section{Resumen}

La piscicultura ha sufrido sucesivas transformaciones, consolidándose como una actividad importante en la agroindustria nacional. Destaca la creación de tilapia, una especie exótica, con un paquete tecnológico definido. Sin embargo, se le ha dado poca importancia al conocimiento del aspecto económico de esta actividad, identificando la composición del costo de producción y los principales parámetros que influyen en su rentabilidad, principalmente el gasto en piensos, que puede llegar al $80 \%$ del costo total de producción. El presente trabajo tuvo como objetivo analizar los costos y la viabilidad económico-financiera en la producción de tilapia del Nilo en diferentes sistemas de crianza en propiedades en el Estado de Río de Janeiro, para ello se realizaron 10 propiedades de diferentes tamaños, estructuras que permitieron un mejor entendimiento. analizó la realidad económica y zootécnica de la piscicultura en el estado de Río de Janeiro. El costo promedio de producción fue de R \$4,51 / kg de pescado vivo. La ración representa el $66,21 \%$ de los costes de producción, seguida del $11,49 \%$ de los costes laborales. El valor medio de recuperación de la inversión encontrado fue de 0,65 años. El Valor Actual Neto, por su parte, presentó un resultado promedio de R \$161.161,35 a una tasa mínima de atractivo del 10\% a.a., a 10 años, con una Tasa Interna de Retorno del $188 \%$. A partir de los resultados encontrados para el análisis de costos, índices zootécnicos y la viabilidad financiera de las piscifactorías de tilapia del Nilo en la región del Fluminense Sur, se verificó que la producción de este pez por parte de los productores estudiados es rentable.

Palabra clave: Costo; Piscicultura; Viabilidad económica.

\section{Introdução}

Nos últimos anos, a aquicultura tem passado por sucessivas transformações, se consolidando como uma importante atividade no agronegócio nacional. Em 2019, a aquicultura brasileira produziu cerca de 758.006 toneladas de peixe, dividida entre a produção de peixes, camarões e moluscos, gerando uma renda de, aproximadamente, R\$ 7 bilhões destacamos a tilapicultura, responsável por 57\% desta produção, o que coloca o Brasil como $4^{\circ}$ maior produtor de tilápia (Peixe BR, 2020).

Fatores como a crise da pesca extrativa e o aumento na demanda de alimentos, colocam a piscicultura como um dos pilares na produção de alimentos e como alternativa econômica para produtores rurais (FAO, 2004).

A piscicultura tem grande importância no fornecimento de proteína de origem animal, auxiliando na segurança alimentar da população, assim como na geração de empregos e renda, sendo previsto aumento do consumo de peixe nesta década, podendo chegar a $15 \%$ de incremento até 2030, tendência que deve ser consolidada através da produção sustentável e gerenciamento da pesca. (FAO, 2020).

A piscicultura é uma atividade que apresenta enorme potencial de crescimento em território brasileiro, devido à disponibilidade hídrica, clima favorável e crescentes melhorias no manejo e nos insumos utilizados na produção (Barros, 2011).

De acordo com Scorvo Filho (2004) a piscicultura pode ser classificada em três tipos de sistemas de criação: extensivos, semi-intensivos e intensivos, sendo o primeiro utilizado por pequenos produtores e em pequenas áreas de espelho d'água, não possuindo fornecimento de ração comercial, havendo dependência do alimento natural. É uma criação de baixa densidade e produtividade, e a produção estimada é em torno de $300 \mathrm{~kg} / \mathrm{ha} / \mathrm{ano}$.

Ainda de acordo com Scorvo Filho (2004) o sistema semi-intensivo: é o mais utilizado no Brasil, caracterizado pelo fornecimento de ração associado a tecnologias de manejo, como o controle da quantidade e qualidade da água. Neste sistema, a 
forma de criação mais comum é a criação em viveiros escavados, com densidade média garantindo produção de, aproximadamente, $12.000 \mathrm{~kg} / \mathrm{ha} / \mathrm{safra}$. Já para o sistema intensivoutiliza-se exclusivamente ração balanceada, alta densidade de peixes e grande volume de água com renovação constante. É normalmente encontrado na forma de criação em tanques-rede, que podem garantir uma produção média de $50 \mathrm{~kg} / \mathrm{m}^{3} / \mathrm{safra}$.

Para a piscicultura, dentre as mais de 25.000 espécies de peixes, destaca-se a tilápia do Nilo (Oreochromis niloticus) como um dos peixes de maior potencial para a criação (Zimmermann \& Harper, 2003).

A tilápia, espécie exótica e rústica, é o peixe mais cultivado no Brasil (Nogueira, 2004). apresenta boa adaptabilidade, carne saborosa, crescimento rápido, alta produtividade e prolificidade, e com um pacote tecnológico avançado e definido. No Estado do Rio de Janeiro, a criação dessa espécie apresenta grande potencial para o desenvolvimento comercial e como fonte de proteína para os que vivem da agricultura familiar.

A criação de tilápias vem ganhando grande importância no cenário nacional e conquistando cada vez mais adeptos, principalmente pequenos e médios produtores, pelo fato de não necessitar de grandes extensões de terra e por necessitar de baixo investimento.

Além disso, as características geográficas e mercadológicas, somadas a abundância de recursos hídricos, fazem do Estado um excelente atrativo para a aquicultura. Entretanto, para que haja um desenvolvimento sustentável da atividade, a piscicultura deve ser conduzida com critérios técnicos, econômicos, sociais e ambientais, e que respeitem as normas vigentes no país.

Diante deste cenário, torna-se fundamental conhecer os aspectos econômicos da piscicultura, identificando os itens mais relevantes do custo de produção e os principais parâmetros que influenciam em sua rentabilidade.

A análise econômica de produção contribui para identificar os itens relevantes dos custos na atividade, bem como os parâmetros relacionados à rentabilidade em um ciclo de produção (Sabbag et al. 2007). Além disso, os autores descreveram a importância do acompanhamento dos índices zootécnicos, tendo-se, desta forma, precisão de onde o sistema está sendo prejudicado, o que permite análises de soluções que gerem maior eficiência e rentabilidade da atividade.

A importância de o produtor conhecer à maneira como está produzindo, mensurando o custo e a receita da produção, de modo a determinar a produção e a eficiência da atividade é crucial para sua fixação na atividade (Nachiluk \& Oliveira, 2012).

Desta forma, os parâmetros econômicos da atividade devem ser obtidos através das análises de custo de produção e da viabilidade econômico-financeira. A análise de custo de produção deve ser realizada através do levantamento de dados de uma atividade em funcionamento. Analisaram ainda que, para o planejamento da atividade em longo prazo, se faz necessário a análise da viabilidade econômico-financeira (Peres et al. 2016).

$\mathrm{Na}$ análise do custo de produção da atividade podem-se utilizar distintas metodologias. O custo operacional de produção como alternativa para essa análise foi abordado (Matsunaga et al. 1976) e Hoffmann (1987) descreveu a análise do custo total, podendo ser dividido em custos fixos e variáveis e por fim, apresentaram o custo de produção e a análise de rentabilidade (Lopes \& Carvalho, 2002).

O presente trabalho teve por objetivo analisar os custos e a viabilidade econômico-financeira na produção de tilápias do Nilo em diferentes sistemas de criação em propriedades no Estado do Rio de Janeiro.

\section{Metodologia}

Os dados analisados neste estudo foram obtidos do arquivo de informações da Fundação Instituto de Pesca do Estado do Rio de Janeiro (FIPERJ). A autorização para o uso dos dados foi por meio do documento de comunicação interna “CI 
FIPERJ/CEXT-DPP SEI N²9”, assinado em 07 de julho de 2020. Estes dados foram coletados ao decorrer do ano (safra) de 2019.

O órgão é responsável pela assistência técnicas às propriedades rurais do estado que possuem atividades pesqueiras e de aquicultura. Todas as informações de dados cadastrais pessoais dos produtores foram preservadas e não utilizadas no trabalho. Dados de 10 propriedades de diferentes tamanhos, estruturas e volume de produção foram avaliados, desta forma permitindo uma melhor estimativa e compreensão da realidade econômica e zootécnica da piscicultura no Estado do Rio de Janeiro.

Foram selecionadas 10 propriedades, divididas em cinco propriedades com produção de tilápias em tanques-rede e outras cinco propriedades com produção em viveiros escavados.

$\mathrm{Na}$ construção das planilhas de fluxo de caixa (quantidade x preço) foram inseridas as informações técnicas e econômicas das propriedades, caracterizando o sistema de produção explorado, e posteriormente realizada a análise de custos de produção.

O valor do inventário dos bens imobilizados inicial e final foi calculado a partir da quantidade de cada item convertida a valor imobilizado aplicando-se preço de mercado (referente ao ano de 2019), de acordo com o proposto por Aguiar \& Almeida (2002).

Após o levantamento das informações e a quantificação necessária para a produção de tilápia foi realizada a tabulação dos dados nas planilhas eletrônicas do "Microsoft-Excel ${ }^{\circledR}$ ", de acordo com o horizonte estudado (uma safra). Posteriormente esses dados foram analisados econômica e estatisticamente.

A avaliação dos custos de produção foi baseada na metodologia de custo operacional proposto por Matsunaga et al. (1976), e que tem como princípio a análise dos custos em curto prazo (um ciclo de produção).

\section{Determinação dos custos de produção e análise financeira}

Para realização da análise do custo de produção e análise financeira foram levantados os dados referentes à infraestrutura de produção, itens, quantidade, preço e vida útil, assim como os dados referentes ao manejo, operações, mão de obra, insumos, equipamentos e manutenção.

Com os resultados obtidos montou-se um banco de dados no programa Microsoft Excel®, contendo os cálculos e fórmulas utilizadas gerando gráficos e tabelas.

Para o cálculo do custo de produção, considerou-se a estrutura do custo operacional de produção proposta por Matsunaga et al. (1976). Este é composto de Custo Operacional Efetivo (COE), com a utilização dos insumos, e o Custo Operacional Total (COT), resultante do COE acrescido das despesas com depreciação linear de máquinas e equipamentos e encargos financeiros.

$\mathrm{Na}$ análise de custos de produção foram definidos os principais itens do fluxo de caixa. A partir dos itens do fluxo de caixa obtêm-se os componentes da análise dos custos de produção: custo operacional efetivo, custo operacional total e custo total de produção, descritos a seguir:

Custo Operacional Efetivo (COE): é a soma de todos os gastos diretamente relacionados com a produção, que se mantêm inalterado. O COE Será calculado somando-se as despesas como mão de obra, luz, telefone, combustível, insumos (ração, adubo, medicamento, alimentação, etc.), contabilidade, aquisição de equipamentos e quaisquer outros gastos.

Custo Operacional Total: após calcular os custos com despesas operacionais efetivas, despesas que exigirão o desembolso monetário, foram calculadas o custo operacional total somando-se o custo operacional efetivo à depreciação de 
benfeitorias, maquinários e equipamentos. O resultado serve como mostra dos valores que o produtor deverá economizar anualmente para repor os recursos de produção ao final de sua vida útil.

Custo Total de Produção: Para este cálculo será utilizada a metodologia citada por Martin et al. (1997). Nesta estrutura de custo de produção, além dos desembolsos ocorridos no processo produtivo, são consideradas as depreciações dos itens de capital fixo, bem como as remunerações ou custos oportunidades dos fatores de produção empregados. A depreciação das benfeitorias, máquinas e equipamentos foi realizada através do método linear, considerando o valor de sucata igual a zero após 10 anos de uso. Para remuneração do capital investido utilizou-se a Taxa Selic para o período de estudo (2019) com juros de $6 \%$ a.a. sobre o valor do capital fixo médio investido.

Através dos itens que compõe o fluxo de caixa podem-se analisar os indicadores de eficiência econômica, receita bruta, receita líquida, margem bruta, margem líquida, resultado (lucro ou prejuízo), lucratividade e rentabilidade. Para isso, seguiu-se o modelo utilizado por Martin (1997), descrito a seguir:

Receita Bruta (RB): é o valor total obtido nas vendas da produção, é dada pelo preço unitário médio pago aos produtores multiplicado pela quantidade comercializada.

$\boldsymbol{R B}=\boldsymbol{P t} \boldsymbol{x} \boldsymbol{P u}(P t:$ produção total da atividade; $P u$ : preço unitário)

Receita Líquida (RL): é a diferença entre a receita bruta e o custo operacional total de produção. O indicador do resultado aponta as condições financeiras da atividade medindo a lucratividade no curto prazo.

$\boldsymbol{R} \boldsymbol{L}=\boldsymbol{R B}-\boldsymbol{C O T}(R B:$ receita bruta; $C O T:$ custo operacional total)

Margem Bruta (MB): é a margem em relação ao custo operacional total, isto é, o resultado obtido após o produtor arcar com o custo operacional, considerando a receita bruta. Indica qual a disponibilidade para cobrir os riscos da produção.

$M B=(R B-C O T) / C O T x 100(R B:$ receita bruta; COT: custo operacional total)

Resultado (R): é a diferença entre as receitas e os custos. É observado lucro quando ele for positivo, o que significa que a atividade conseguiu quitar o custo total de produção. Caso seja negativo é considerado prejuízo.

$\boldsymbol{R}=\boldsymbol{R} \boldsymbol{B}-\boldsymbol{C T P}(R B:$ receita bruta; $C T P:$ custo total de produção)

Índice de lucratividade (IL): esse indicador mostra a relação entre o lucro operacional e a receita bruta, em percentagem. É uma medida importante de rentabilidade da atividade agropecuária, uma vez que mostra a taxa disponível de receita da atividade após o pagamento de todos os custos operacionais e é dado em porcentagem.

$\boldsymbol{I L}=(\boldsymbol{R L} / \boldsymbol{R B}) \boldsymbol{x} \mathbf{1 0 0}(R L:$ receita líquida; $R B$ : receita bruta)

Ponto de Equilíbrio ou Ponto de Nivelamento (PE): indica qual a produção mínima necessária para cobrir o custo operacional total, dado o preço de venda unitário. É a produção mínima que deve ser comercializada, obtendo receita que seja igual aos custos.

$\boldsymbol{P E}=\boldsymbol{C O T} / \boldsymbol{P u}(C O T$ : custo operacional total; $P u$ : preço unitário $)$ 
Payback: é o índice que determina qual o tempo necessário para o produtor recuperar o investimento econômico que fez no empreendimento, ou seja, o tempo para reaver o capital investido.

$$
\sum_{i=0}^{k} \frac{(R B-C O T)}{(1+i)^{\mathrm{n}}} \geq 0
$$

(RB: receita bruta; $C O T$ : custo operacional total; $k$ : período de recuperação do capital; $i$ : taxa mínima de atratividade; $j$ : número de ciclos de produção; $n$ : período de tempo).

Os indicadores utilizados no cálculo de viabilidade econômica utilizados neste estudo foram o valor presente líquido, com a taxa mínima de atratividade fixada em $10 \%$ a.a. e a taxa interna de retorno.

O Valor Presente Líquido (VPL) é obtido subtraindo-se o investimento inicial do valor presente nas entradas do fluxo de caixa, descontadas a uma taxa que é igual ao custo de capital. Ele é utilizado para se avaliar um investimento, caso o VPL seja maior que zero, o projeto é aceito, caso contrário será rejeitado.

$$
V P L=\sum_{j=0}^{k} \frac{(R B-C O T)}{(1+i)^{\mathrm{n}}}
$$

(RB: receita bruta; $C O T$ : custo operacional total; $i$ : taxa mínima de atratividade; $j$ : número de ciclos de produção; $n$ : período de tempo).

Taxa Interna de Retorno (TIR) é o valor da taxa mínima de atratividade que faz com que o VPL seja igual a zero, ou seja, onde o investimento inicial é igual às entradas de caixa. Desta forma, a TIR caracteriza a taxa de retorno de um determinado período.

$$
\sum_{i=0}^{k} \frac{(R B-C O T)}{(1+T i r)^{\mathrm{n}}} \geq 0
$$

(RB: receita bruta; COT: custo operacional total; Tir: taxa interna de retorno; $j$ : número de ciclos de produção; $n$ : período de tempo).

\section{Determinação dos índices zootécnicos}

Os indicadores zootécnicos foram baseados nos dados coletados através das informações obtidas dos produtores avaliados.

Peso Total Despescado (PTD) é o somatório dos valores obtidos ao final da pesagem do lote de peixes abatidos. É dado em quilogramas ou toneladas.

Peso Médio Final (PMF) refere-se ao peso médio do peixe ao abate. É calculado através do peso total despescado dividido pelo número de peixes despescados. É expresso em quilogramas por unidade (kg/un).

$\boldsymbol{P M F}=\boldsymbol{P T D} / \boldsymbol{N p d}(P T D:$ peso total despescado; $N p d:$ número de peixes despescados) 
A Densidade de Estocagem (DE) ou Biomassa é a quantidade de peixes estocados no ambiente de criação. Normalmente é expressa em biomassa por unidade de área, dada em $\mathrm{kg}$ por $\mathrm{m}^{2}$ no caso de viveiros escavados ou volume em $\mathrm{kg}$ por $\mathrm{m}^{3}$ no caso de tanques-rede.

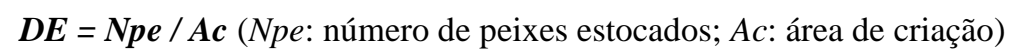

Taxa de Sobrevivência (TS) é a quantidade final de peixes no ciclo de produção dividida pela quantidade inicial, estimada em porcentagem.

$T S=(Q f / Q i) x 100$ (Qf: quantidade final de peixes; Qi: quantidade inicial de peixes).

Conversão Alimentar (CA) é obtida por meio do cálculo da quantidade total de ração fornecida dividida pelo ganho de peso dos peixes no final do ciclo de produção, ou em cada fase de vida do peixe. Através dessa informação podemos informar a quantidade de ração (kg) utilizada para produzir 01 (um) quilo de peixe vivo.

$\boldsymbol{C A}=($ Qrf / Pie $-\boldsymbol{P f e})$ (Qrf: quantidade de ração fornecida; Pie: peso inicial estocado; Pfe: peso final estocado).

\section{Resultados}

Na Tabela 1 estão discriminadas algumas informações gerais sobre os empreendimentos estudados.

Tabela 1. Dados gerais das propriedades rurais com pisciculturas fluminenses em relação ao tamanho das unidades de criação $\left(\mathrm{m}^{2}\right.$, número de unidades de criação, área total de produção $\left(\mathrm{m}^{2}\right)$, número de peixes por safra por ano, número de peixes ao ano.

\begin{tabular}{|c|c|c|c|c|c|c|c|c|c|c|}
\hline Propriedade & TR 1 & TR 2 & TR 3 & TR 4 & TR 5 & VE 1 & VE 2 & VE 3 & VE 4 & VE 5 \\
\hline $\begin{array}{l}\text { Tamanho das unidades de } \\
\text { criação }\left(\mathrm{m}^{2}\right)\end{array}$ & 4 & 4 & 4 & 9 & 4 & 2.333 & 2.143 & 1.200 & 1.750 & 588 \\
\hline $\mathrm{N}^{o}$ de unidades de criação & 3 & 2 & 10 & 5 & 6 & 3 & 7 & 5 & 2 & 4 \\
\hline $\begin{array}{l}\text { Área total de produção } \\
\left(\mathrm{m}^{2}\right)\end{array}$ & 12 & 8 & 40 & 45 & 24 & 7.000 & 15.001 & 6.000 & 3.500 & 2.352 \\
\hline $\mathrm{N}^{\circ}$ de peixes / safra & 2.100 & 1.000 & 5.000 & 5.000 & 3.900 & 15.000 & 32.500 & 12.000 & 5.000 & 10.000 \\
\hline Safras /ano & 2 & 2 & 1 & 1 & 1 & 1 & 1 & 1 & 1 & 1 \\
\hline $\mathrm{N}^{\circ}$ de peixes / ano & 4.200 & 2.000 & 5.000 & 5.000 & 3.900 & 15.000 & 32.500 & 12.000 & 5.000 & 10.000 \\
\hline
\end{tabular}

Fonte: Autores.

A Tabela 1 traz o tamanho médio de cada unidade produtiva, o número de unidades dentro de cada propriedade, assim como a área total para criação dos peixes.

A área de produção para os tanques rede é dada em $\mathrm{m}^{3}$, uma vez que cada tanque rede possui a altura de 1 metro. Já a área dos viveiros escavados é dada em $\mathrm{m}^{2}$.

Na sequência, a Tabela 1 discrimina a quantidade de peixes utilizados em cada safra. A safra é o período que compreende o processo produtivo desde a entrada das formas jovens dos peixes, sendo alevinos ou juvenis, até o momento da despesca final para comercialização dos peixes adultos. Nota-se que dentre as dez propriedades analisadas, apenas duas delas 
conseguem fazer mais de uma safra por ano (período de 12 meses). Este fato está associado ao melhor manejo alimentar observado nessas propriedades, o que gera maior eficiência alimentar.

Apesar das propriedades TR1 e TR2 apresentarem duas safras no ano, os valores de produção adotados foram referentes a uma safra, permitindo a comparação dos dados com as demais propriedades.

Os índices zootécnicos analisados foram: densidade de estocagem, taxa de sobrevivência, quantidade de peixes comercializados, peso médio final e peso total, conversão alimentar e a quantidade total de ração utilizada.

Os dados representados na Tabela 2 estabelecem esses valores para cada propriedade.

Tabela 2. Índices zootécnicos e dados gerais das propriedades rurais com pisciculturas no Estado do Rio de Janeiro.

\begin{tabular}{|c|c|c|c|c|c|c|c|c|c|c|}
\hline Propriedade & TR 1 & TR 2 & TR 3 & TR 4 & TR 5 & VE 1 & VE 2 & VE 3 & VE 4 & VE 5 \\
\hline $\begin{array}{l}\text { Área total de produção }\left(\mathrm{m}^{3}\right. \\
\left.\mathrm{e} \mathrm{m}^{2}\right)\end{array}$ & 12 & 8 & 40 & 45 & 24 & 7.000 & 15.001 & 6.000 & 3.500 & 2.352 \\
\hline Formas jovens adquiridas & 2.100 & 1.000 & 5.000 & 5.000 & 3.900 & 15.000 & 35.000 & 12.000 & 5.000 & 10.000 \\
\hline Densidade de Estocagem & 175 & 125 & 125 & 111 & 163 & 2,1 & 2,2 & 2 & 1,4 & 4,3 \\
\hline $\begin{array}{l}\text { Densidade Final de } \\
\text { Estocagem }\end{array}$ & 140 & 100 & 100 & 88,8 & 130,4 & 1,26 & 1,76 & 1,5 & 1,4 & 4,3 \\
\hline Taxa de Sobrevivência (\%) & 95 & 90 & 95 & 90 & 85 & 90 & 93 & 90 & 85 & 88 \\
\hline $\begin{array}{l}\mathrm{N}^{\mathrm{o}} \text { de } \\
\text { comercializados }\end{array}$ & 1.995 & 900 & 4.750 & 4.500 & 3.315 & 13.500 & 32.550 & 10.800 & 4.250 & 8.800 \\
\hline Peso Médio Final (kg) & 0,8 & 0,8 & 0,8 & 0,8 & 0,8 & 0,6 & 0,8 & 0,75 & 1 & 1 \\
\hline Peso total (kg) & 1.596 & 720 & 3.800 & 3.600 & 2.652 & 8.100 & 26.040 & 8.100 & 4.250 & 8.800 \\
\hline $\begin{array}{l}\text { Quantidade de ração } \\
\text { utilizada }(\mathrm{kg})\end{array}$ & 2.075 & 1.080 & 5.700 & 6.120 & 3.715 & 11.340 & 36.456 & 12.150 & 6.375 & 14.960 \\
\hline Conversão alimentar & 1,3 & 1,5 & 1,5 & 1,7 & 1,4 & 1,4 & 1,4 & 1,5 & 1,5 & 1,7 \\
\hline
\end{tabular}

*Área total de produção: $\mathrm{m}^{3}$ para tanques-rede e $\mathrm{m}^{2}$

*Densidade de Estocagem: dada em peixes $/ \mathrm{m}^{3}$ para tanques-rede e peixes $/ \mathrm{m}^{2}$ para viveiros escavados.

*Densidade Final de Estocagem: dada em $\mathrm{kg} / \mathrm{m}^{3}$ para tanques-rede e $\mathrm{kg} / \mathrm{m}^{2}$ para viveiros escavados.

Fonte: Autores.

A Tabela 3 apresenta os custos de implantação do projeto, assim como os gastos durante o ciclo produtivo.

Os valores foram anotados durante todo o processo de produção e recolhidos para análise ao fim da despesca total.

Os gastos referentes à implantação são os valores dispostos para aquisição dos tanques redes e para a construção dos viveiros escavados e demais estruturas.

Os gastos com formas jovens compreendem a aquisição de juvenis de tilápias no caso das propriedades que realizam a produção em tanques rede e na aquisição de alevinos pelos produtores que dispõem dos viveiros escavados para a criação.

A Tabela 4 apresenta os dados referentes às receitas obtidas através da comercialização do peixe.

Nota-se que algumas propriedades se utilizam apenas da venda de peixes vivos, outras adotam a venda do filé e ainda aquelas que contam com ambas as formas de comercialização.

A Tabela 5 apresenta os dados para análise econômica e de viabilidade da produção de tilápias no Estado do Rio de Janeiro. 
Research, Society and Development, v. 10, n. 2, e38010212502, 2021

(CC BY 4.0) | ISSN 2525-3409 | DOI: http://dx.doi.org/10.33448/rsd-v10i2.12502

Os dados analisados são: Receita Bruta, Receita Líquida, Margem Bruta, Resultado, Lucratividade, Rentabilidade, Ponto de Equilíbrio, Payback, Valor Presente Líquido e Taxa Interna de Retorno.

A receita bruta é obtida através da multiplicação da quantidade total comercializada pelo preço médio de venda. A receita líquida é obtida subtraindo-se o custo total de produção da receita bruta obtida. A receita líquida positiva indica que o empreendimento obteve lucro em curto prazo. 
Tabela 3. Custos de implantação e produção das pisciculturas fluminenses para criação de tilápia do Nilo.

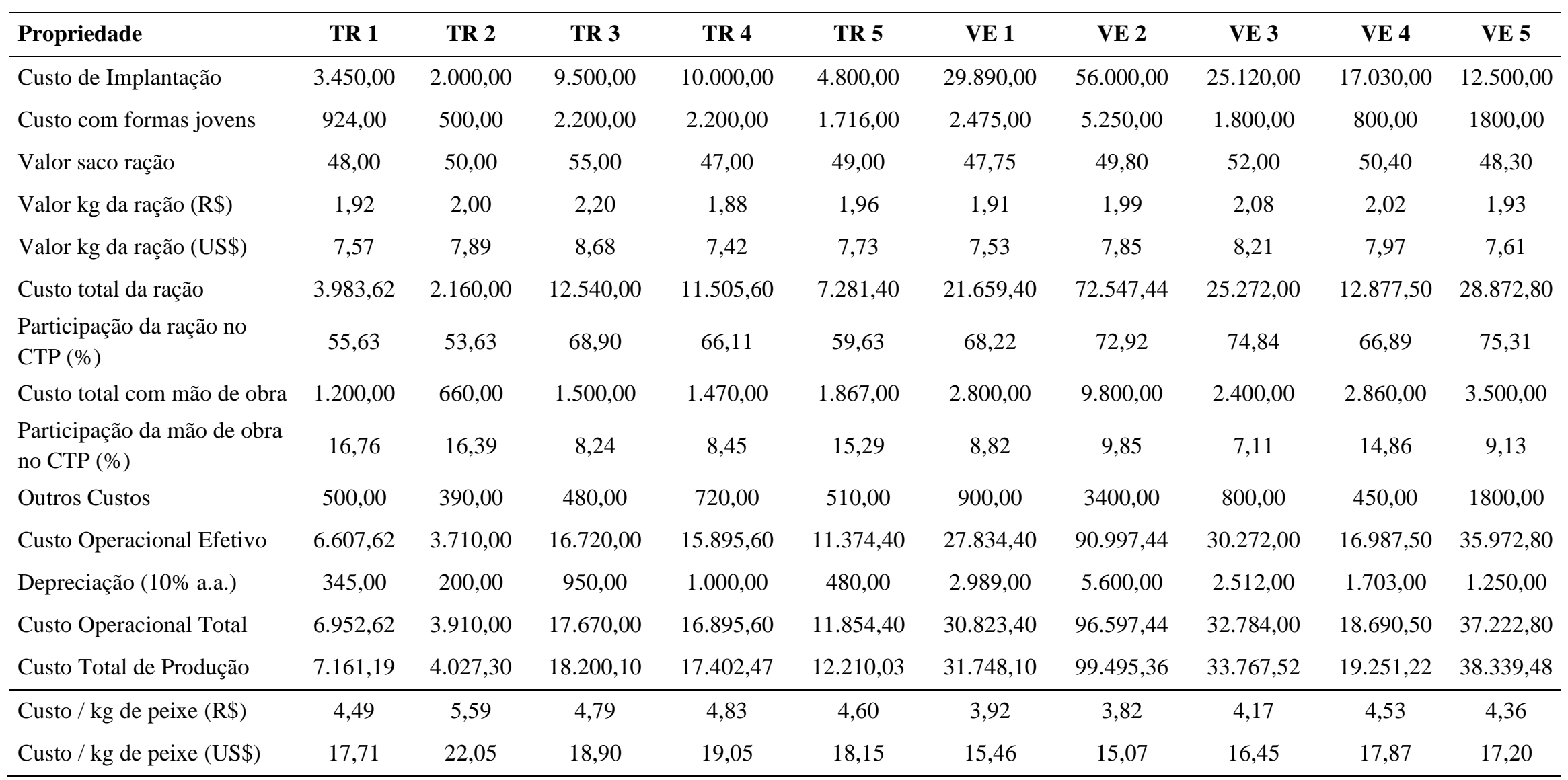

*Valor médio do dólar par o ano de 2019 foi de R \$3,9451, de acordo com o Banco Central. *CTP: Custo Total de Produção

*Outros Custos: material, equipamentos, medicamentos etc.

Fonte: Autores. 
Research, Society and Development, v. 10, n. 2, e38010212502, 2021

(CC BY 4.0) | ISSN 2525-3409 | DOI: http://dx.doi.org/10.33448/rsd-v10i2.12502

Tabela 4. Receitas da criação de tilápia do Nilo das pisciculturas fluminenses em relação à quantidade de peixes vivos, tipo de venda, valor em R\$ do peixe vivo, valor em $\mathrm{R} \$$ do filé, receita bruta com peixe vivo, receita bruta com filé e receita bruta total da criação.

\begin{tabular}{|c|c|c|c|c|c|c|c|c|c|c|}
\hline Propriedade & TR 1 & TR 2 & TR 3 & TR 4 & TR 5 & VE 1 & VE 2 & VE 3 & VE 4 & VE 5 \\
\hline $\begin{array}{c}\text { Peixes } \\
\text { Vendidos }(\mathrm{Kg})\end{array}$ & 1.596 & 720 & 3.800 & 3.600 & 2.652 & 8.100 & 26.040 & 8.100 & 4.250 & 8.800 \\
\hline Tipo de Venda & Variada & Variada & Filé & Filé & vivo & vivo & vivo & variada & vivo & variada \\
\hline $\begin{array}{l}\text { Quilo do Peixe } \\
\text { Vivo }(\mathrm{R} \$)\end{array}$ & 9,00 & 10,00 & - & - & 7,00 & 8,00 & 6,50 & 10,00 & 12,00 & 10,00 \\
\hline $\begin{array}{l}\text { Quilo do Filé } \\
\qquad(\mathrm{R} \$)\end{array}$ & 25,00 & 25,00 & 34,00 & 28,00 & - & - & - & 32,00 & - & 30,00 \\
\hline $\begin{array}{l}\text { Receita Peixe } \\
\text { Vivo (mil R\$) }\end{array}$ & 7,18 & 3,60 & - & - & 18,56 & 64,80 & 169,26 & 40,50 & 51,00 & 44,00 \\
\hline $\begin{array}{l}\text { Receita Filé } \\
\text { (mil R\$) }\end{array}$ & 6,65 & 3,00 & 43,06 & 33,60 & - & - & - & 43,20 & - & 44,00 \\
\hline $\begin{array}{l}\text { Receita Total } \\
\quad(\text { mil R\$) }\end{array}$ & 13,83 & 6,60 & 43,06 & 33,60 & 18,56 & 64,80 & 169,26 & 83,70 & 51,00 & 88,00 \\
\hline
\end{tabular}

Fonte: Autores.

Tabela 5. Análise econômica e viabilidade da produção da criação de tilápia das pisciculturas fluminenses.

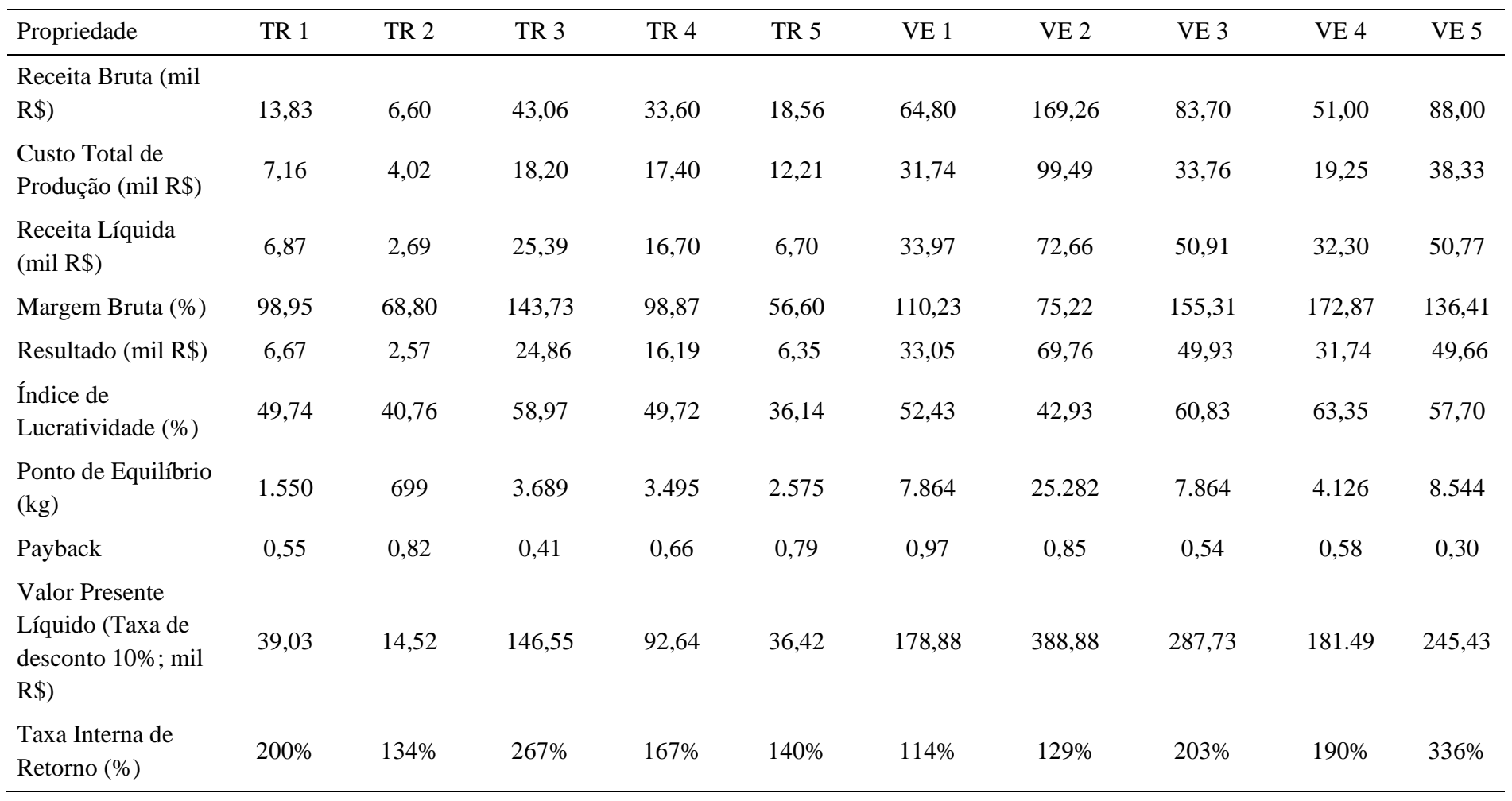

Fonte: Autores 
A margem bruta representa a sobra operacional do empreendimento, servindo como uma forma de analisar a eficiência econômica da propriedade. Ela é expressa em porcentagem e serve para informar o quanto a propriedade está ganhando com a venda de seus produtos.

Os valores obtidos apontam que as propriedades alcançaram bons resultados, principalmente pela venda bem sucedida e com altos valores alcançados. De maneira geral, o peixe foi vendido de forma direta ao consumidor final, alcançando valores relativamente altos.

A margem bruta foi positiva em todas as propriedades, com variação de 56,6\% a 172,87\% e valor médio de $111,7 \%$. Indicam que os altos valores de venda influenciaram de forma direta nas margens observadas.

\section{Discussão}

A densidade de estocagem é a quantidade de peixes por área de criação, essa é apontada como um dos principais pontos críticos da piscicultura. A capacidade de estocagem de um sistema depende do fluxo de água na criação, da concentração de oxigênio dissolvido, do pH, da temperatura da água e outros fatores locais.

A densidade de peixes nos tanques-rede encontrada nas propriedades TR1, TR2, TR3, TR4 e TR5 foi de 175, 125, 125, 111 e 163 peixes $/ \mathrm{m}^{3}$, respectivamente (em sistema monofásico). Os valores indicados em alguns manuais indicam que a densidade para este tipo de criação pode variar de 150 a 250 peixes/m³ (Carriço, 2008; Sandoval Jr, 2009).

A densidade de animais em tanques-rede deve ser de 150 a $250 \mathrm{~kg} / \mathrm{m}^{3}$ (Nogueira, 2007), outro autor cita a densidade na ordem de 30 a $300 \mathrm{~kg} / \mathrm{m}^{3}$, variando de acordo com a qualidade da água e tamanho das estruturas de criação (Kubitza, 2009). Os dados coletados apontam para densidades entre 88,8 e $140 \mathrm{~kg} / \mathrm{m}^{3}$ nos sistemas que utilizam tanques-rede.

Para os viveiros escavados a densidade de estocagem apresentou uma variação entre 1,4 e 4,3 peixes por $\mathrm{m}^{2}$. Os valores de peso por $\mathrm{m}^{2}$ observados foram de 1,26 a $4,3 \mathrm{~kg} / \mathrm{m}^{2}$. Tal variação pode ser explicada pela diferença no aporte e renovação de água encontrada nos viveiros.

A densidade de 1,5 a 2 peixes $/ \mathrm{m}^{2}$ e 0,9 a $1,5 \mathrm{~kg} / \mathrm{m}^{2}$ é indicada para o sistema de criação em viveiros escavados com renovação de água entre 5 e 10\% e sem auxílio de aeradores (Kubitza, 2009). Costa (2010) analisa que a densidade pode variar de 1 a 10 peixes $/ \mathrm{m}^{2}$ de acordo com a renovação de água e o teor de oxigênio disponível.

As taxas de sobrevivência encontradas para as criações em tanques rede foram de 85 a 95\%. De acordo com o Manual de criação de tilápias em tanques rede escrito por Carriço (2008), a taxa de sobrevivência satisfatória deve ser em torno de 90 a 95\%. Indicando que apenas a propriedade TR5 não alcançou os valores ideais.

Para os viveiros escavados foram encontrados valores entre 85 e $93 \%$ de sobrevivência. De acordo com Kubitza (2011), as taxas de sobrevivência aceitáveis para viveiros escavados variam de 88 a 98\%. Verifiou-se que a propriedade VE4 apresentou índice inferior aos mencionados.

A conversão alimentar anotada para as propriedades com criação em tanques rede variou de 1,3 a 1,7. Os valores encontrados na criação em viveiros escavados foram próximos, e variaram de 1,4 a 1,7. A conversão alimentar é um parâmetro fundamental para avaliar se o arraçoamento está sendo realizado de forma eficaz. Ela pode ser influenciada por diversos fatores, mas principalmente pela fase de vida, idade e tamanho dos peixes; pela qualidade da água; qualidade e propriedades da ração; temperatura da água; densidade e estresse dos peixes.

A conversão alimentar da tilápia em viveiro escavado pode variar de 1 a 1,8 (Kubitza, 2011), esse valor pode ser diretamente influenciado pelo oxigênio dissolvido presente na água e o manejo de adubação realizado pelo produtor. Para criação em tanques rede, as taxas de conversão alimentar podem variar de 1 a 2,0 (Carriço, 2008). Ainda de acordo com o 
autor anterior, a taxa de conversão irá influenciar diretamente no custo de produção, uma vez que influencia na quantidade de ração utilizada na produção.

O peso dos peixes ao abate/comercialização apresentou média de 0,8 kg para os criatórios em tanques rede, e variou de 0,6 a $1 \mathrm{~kg}$ para as propriedades com viveiros escavados.

O gasto total com ração foi anotado a partir das notas fiscais de compra e seu devido uso na produção. O valor total da ração foi comparado com o Custo Total de Produção, que é composto dos gastos realizados durante o período de produção (Matsunaga, 1976). Esses valores indicam a parcela dos custos de produção que correspondem aos gastos com ração. A partir deste cálculo conferimos a participação da ração nos gastos da atividade. A proporção dos gastos com ração relacionados ao Custo Total de Produção verificada para as propriedades com criação em tanques-rede variou de 53,63 a 68,90\%. Para as criações em viveiros escavados foram identificados os valores de 66,89 a 75,31\%.

Analisando os custos da criação de tilápias no Estado de São Paulo, Carneiro (1999) observou que a ração obteve uma participação de 63,47\% no custo total de produção. Furnaleto et al. (2006) e Moraes (2008) observaram uma participação de71 e $67,1 \%$ da ração sobre os custos da tilápia em tanques rede, respectivamente.

Para criação de tilápias em viveiros escavados, um estudo no Estado do Paraná e destacou o gasto com ração como o principal fator dos custos operacionais com uma média de 52,1\% (Andrade, 2005). Quanto ao preço médio da ração, Campos et al. (2007) e Sabbag et al. (2007) obtiveram o valor de R $\$ 0,82$ e R $\$ 0,80$, respectivamente, por quilo de ração adquirida no Estado de São Paulo. Em análises de custos no Estado do Paraná obteve um valor médio de R\$0,70 (Silva et al. 2012). No Estado do Pará, Brabo et al. (2013) indicou um preço médio de R \$1,90 para este insumo. O atual trabalho obteve o valor médio de R $\$ 1,99$ (US\$7,85) por quilo de ração adquirida.

O alto valor encontrado para ração pode ser explicado pelo fato dos insumos e ração serem importados de outros Estados. Os valores gastos com transporte, além dos impostos inferidos no produto os tornam demasiadamente caros se comparados com outras regiões do Brasil. Dessa forma, se faz necessário avaliar políticas públicas como isenção de impostos, maior incentivo na produção, entre outros, para buscar a redução deste custo da ração no Estado do Rio de Janeiro. De acordo com o trabalho realizado, o segundo item que mais onera a produção de tilápias são os gastos com mão de obra. Esses gastos representaram 13,02 e 9,95\% do custo total de produção para criação em tanques rede e viveiros escavados, respectivamente. Valores superiores aos indicados por Brabo (2013) para a criação de tilápias em tanques-rede, onde encontrou uma média de 6,84\% de gastos com mão de obra. Em contrapartida ficaram abaixo dos valores citados por Campos (2007) para o mesmo sistema, 14,96\%. Para a criação em viveiros escavados, Boechat (2015) apresentou valores médios de 29\%, enquanto Leonardo et al. (2018) obteve proporção de 9,16\% dos custos de mão de obra em relação ao custo total de produção.

O Custo Operacional Efetivo (COE) é decorrente da soma de todas as despesas diretas realizadas durante o processo de produção. Ele inclui os gastos com aquisição de formas jovens (alevinos ou juvenis), compra de ração e demais insumos, gastos com mão de obra, combustível, equipamentos, etc. O Custo Operacional Total (COT) é o resultado do somatório do COE e os encargos sociais e depreciação das estruturas, de equipamentos e aparelhos. O valor adotado para se estabelecer a depreciação dos bens foi de $10 \%$ ao ano.

O Custo Total de Produção é o resultado do COT mais o custo de oportunidade do capital. Para este modelo foi adotado a taxa Selic de 6\% a.a. referente ao valor observado para o ano 2019.

Por fim, temos o custo de produção. Valor gasto para produzir 1 (uma) unidade do produto, neste caso é o valor necessário para se produzir 1 (um) quilo de tilápia. Para as criações realizadas em tanques rede encontramos custo médio de produção de R\$4,86 (US\$19,17). Ou seja, é necessário um investimento de R\$4,86 (US\$19,17) para se produzir 1 (um) quilo 
de tilápia em tanques rede no Estado do Rio de Janeiro. Por sua vez, a produção de tilápias em viveiros escavados teve um custo médio de $\mathrm{R} \$ 4,16 / \mathrm{kg}$.

Campos et al. (2007) analisando os custos de produção de tilápias em tanques rede obtiveram os valores de $\mathrm{R} \$ 2,05$ e $\mathrm{R} \$ 2,30 / \mathrm{kg}$ em São Paulo, respectivamente. Neste mesmo sistema de produção, Moraes (2008) e Furlaneto et al. (2009) apontaram o custo médio de R \$2,20 em Santa Catarina e R \$2,10/kg em São Paulo, respectivamente.

A análise de três sistemas com diferentes números de tanques-rede no Pará e observou que o custo médio de produção diminuía conforme a produção era aumentada, e obteve resultados que variaram entre $\mathrm{R} \$ 5,99$ e $\mathrm{R} \$ 6,59$, Brabo et al. (2013). Os resultados encontrados foram superiores aos resultados de custo de produção averiguados no atual trabalho.

Para o sistema de produção em viveiros escavados, Sabbag (2007) obteve um custo médio de R $\$ 1,98 / \mathrm{kg}$ em São Paulo. No ano de 2015, Boechat analisou o valor de R \$5,97 para cada quilo produzido no Espírito Santo. Trombeta et al. (2016) e Leonardo et al. (2018) apresentaram custo de produção para tilápia de R \$4,49 no Distrito Federal e R \$5,64 em São Paulo, respectivamente. Valores superiores à média obtida neste trabalho.

O preço médio de venda do peixe vivo foi de $\mathrm{R} \$ 9,06 / \mathrm{kg}$ (US\$35,74). Valor obtido utilizando-se da média de preço praticado por cada propriedade. Valor superior ao observado por Brabo et al. (2013), que identificaram o preço de venda de R \$5,00 no Pará e R \$7,00/ kg em Goiás, respectivamente. Boechat (2015) analisando uma piscicultura no norte do Estado do Espírito Santo verificou o preço de venda do peixe vivo a $\mathrm{R} \$ 8,00 / \mathrm{kg}$.

$\mathrm{O}$ alto valor de venda observado neste trabalho pode ser explicado pelo fato dos produtores analisados adotarem a tática de venda direta ao consumidor final, possibilitando a venda do peixe por um valor superior ao que seria obtido na venda atacadista em larga escala. Tal processo de comercialização só é possível devido a reduzida quantidade de peixes produzidos.

O preço médio de venda do filé de tilápia foi de $\mathrm{R} \$ 29,00$ (US\$114,41). Figueiredo Júnior (2008) relatou que os produtores do Estado do Acre recebiam entre R $\$ 24$ e $\mathrm{R} \$ 26 / \mathrm{kg}$ de filé.

A análise de três empreendimentos com 8, 16 e 24 tanques rede obteve margem bruta de 6,15\%, 14,14\%, e 16,94\% Brabo et al. (2013).

Leonardo et al. (2018) analisando cinco propriedades no Vale do Ribeira, em São Paulo, obteve uma média de 2,28\% através dos seguintes valores: $-53,91 \% ;-13,47 \% ; 8,47 \% ; 28,82 \% ; 41,48 \%$.

Resultado é a diferença entre as receitas e os custos da produção. Os resultados alcançados foram positivos variando de $\mathrm{R} \$ 2.572,70$ e $\mathrm{R} \$ 69.764,64$, indicando que as propriedades alcançaram lucro na atividade.

A Lucratividade demonstra o percentual da receita obtida através da venda da produção, ou seja, é a taxa disponível da receita após o pagamento de todas as despesas. As propriedades analisadas apresentaram valor médio de 51,26\% de lucratividade. Valor próximo ao encontrado por Freitas (2015) que, analisando a viabilidade de implantação de uma piscicultura no Estado de Rondônia, obteve uma lucratividade de 55,9\% para o projeto.

O Ponto de Equilíbrio define qual deve ser a produção mínima capaz de arcar com todos os custos de produção. Neste caso ele informa quantos quilos de tilápia deve-se produzir para custear todo o processo produtivo. O ponto de nivelamento varia de acordo com o Custo Operacional Total e o custo de produção por quilo de peixe.

Payback é o tempo necessário para o produtor reaver todo capital investido no empreendimento. Tirando uma média entre as propriedades analisadas, temos um período para retorno do capital investido de 0,65 anos. Campos (2007) avaliando um empreendimento de criação de tilápias em tanques rede em São Paulo obteve o payback de 1,7 anos. Período de retorno ainda maior foi verificado por Brabo et al. (2013), que após analisar 3 empreendimentos com 8, 16 e 24 tanques rede conseguiu payback de 6,$5 ; 3,8$ e 3,3 anos, respectivamente. 
O fato do payback das propriedades analisadas neste trabalho serem tão baixos pode ser explicado através de dois fatores. O primeiro fator foi o alto valor de comercialização do peixe, uma vez que todos realizam a venda direta ao consumidor final e conseguem bons resultados. O segundo fator é que não há um índice ou valor para aquisição da área de produção, ou seja, as propriedades não foram adquiridas para fim comercial da piscicultura. Nas propriedades avaliadas a piscicultura é uma atividade secundária se caracterizando como uma atividade para agregação de renda, estando em primeiro plano a pecuária leiteira ou de corte. Desta forma o investimento inicial foi mais baixo do que de costume.

Para o cálculo do Valor Presente Líquido (VPL) foi utilizada uma taxa mínima de atratividade de $10 \%$ e um período de 10 anos. Caso o VPL seja positivo, significa que o projeto foi aprovado. Todos os modelos avaliados apresentam valores positivos para esse item.

Taxa Interna de Retorno (TIR) caracteriza a taxa de retorno do capital dentro de um determinado período, sendo utilizada para se avaliar um empreendimento. É a taxa de juros que deve ser aplicada ao capital investido para que a receita seja igual aos gastos.

A TIR média para as propriedades analisadas foi de 188\%. Os valores encontrados foram superiores aos valores observados por Campos (2007) e Boechat (2015), que obtiveram taxa interna de retorno de $57 \%$ e $71 \%$ respectivamente. A alta taxa interna de retorno também pode ser explicada pelo baixo investimento inicial, uma vez que não se fez aquisição de propriedades.

\section{Considerações Finais}

A partir da análise da viabilidade econômico-financeira das pisciculturas fluminenses, é possível afirmar que há rentabilidade econômica na criação de tilápia do Nilo no Estado do Rio de Janeiro, Brasil como atividade secundária de uma propriedade rural. Pesquisas nesse campo de atuação devem ser realizadas de forma continuada para efeitos comparativos.

\section{Agradecimentos}

A Fundação Instituto de Pesca do Estado do Rio de Janeiro pelo compartilhamento das informações e dados utilizados no trabalho e pela liberação do autor principal para execução do mesmo.

\section{Referências}

Andrade, R. L. B., Wagner, R. L., Mahl, I., \& Martins, R. S. (2005) Custos de produção de tilápias (Oreochromis niloticus) em um modelo de propriedade da região oeste do Estado do Paraná, Brasil. Ciência Rural, 35 (1), 198-203. https://doi.org/10.1590/S0103-84782005000100032

Aguiar, A P. A.\& Almeida, B. H. P. J. F. (2012) Planejamento e administração da produção de leite e carne no Brasil. Uberaba, MG: FAZU, 92 p.

Araújo, H. S., Sabbag, O. J., Lima, B. T. M., Andriguetto, C. \& Ruiz, U. S. (2012) Aspectos econômicos da produção de bovinos de corte. Pesquisa Agropecuária Tropical, 42 (1), 82-89. https://doi.org/10.1590/S1983-40632012000100012

Ayroza, L. M. S., Romagosa, E., Rezende, D. M. M., Scorvo Filho, J. D., \& Salles, F.A. (2011) Custos e rentabilidade da produção de juvenis de tilápia do Nilo em tanques rede utilizando-se diferentes densidades de estocagem. Revista Brasileira de Zootecnia, 40 (2), 231-239. http://dx.doi.org/10.1590/S151635982011000200001

Barros, A. F., Martins, M. I. E. G., Abreu, J. S. \& Amaral, C. M. C. (2010) Investimento com implantação e custo de produção em pisciculturas no Estado de Mato Grosso. Cáceres: UNEMAT. 92p.

Barros, A. F., Martins, M. I. E. G. \& Souza, O. M. (2011) Caracterização da piscicultura na microrregião da baixada cuiabana, Mato Grosso, Brasil. Boletim do Instituto de Pesca, 37 (3) 261 - 273. https://www.pesca.sp.gov.br/37_3_261-273.pdf

Boechat, F. P., Rodrigures, D. A., Ribeiro, G. M., \& Freitas, R. R. (2015) Avaliação econômica de uma atividade piscícola de água doce no norte do Espírito Santo, Brasil. Actapesca, 3 (1), 10-23. https://doi.org/10.2312/Actafish.2015.3.2.10-23 
Research, Society and Development, v. 10, n. 2, e38010212502, 2021

(CC BY 4.0) | ISSN 2525-3409 | DOI: http://dx.doi.org/10.33448/rsd-v10i2.12502

Brabo, M. F., Flexa, C. E., Veras, G. C., Paiva, R. S. \& Fujimoto, R. Y. (2013) Viabilidade econômica da piscicultura em tanques-rede no reservatório da usina hidrelétrica de Tucuruí, estado do Pará. Informações Econômicas, 43 (3), 56-64. http://www.iea.sp.gov.br/ftpiea/publicacoes/ie/2013/tec6-0613.pdf

Campos, C. M., Ganeco, L. N., Castellani, D., \& Martins, M. I. E. (2007) Avaliação econômica da criação de tilápias em tanque-rede, município de Zacarias, São Paulo. Boletim do Instituto de Pesca, 33 (2), 265 - 271. https://www.pesca.sp.gov.br/33_2_265-271.pdf

Carneiro, P. C., Martins, M. I. E. G. \& Cyrino, J. E. P. (1999) Estudo de caso da criação comercial da tilápia vermelha em tanques-rede: Avaliação econômica. Informações Econômicas, 29 (8), 52-61. http://www.iea.sp.gov.br/ftpiea/ie/1999/tec3-0899.pdf

Carriço, J. M. M., Nakanishi, L. I. T. \& Chammas, M. A. (2008) Manual do Piscicultor-Produção de Tilápia em Tanque-Rede. SEBRAE, 39 p.

Cavero, B. A. S., Pereira-Filho, M., Roubach, R., Ituassú, D. R., Gandra, A. L., \& Crescêncio, R. (2003) Efeito da densidade de estocagem na homogeneidade do crescimento de juvenis de pirarucu em ambiente confinado. Pesquisa Agropecuária Brasileira, 38 (1), 103-107. https://doi.org/10.1590/S0100204X2003000100014

Araújo, A. P. B., Costa, R. N. T., Lacerda, C. F. \& Gheyi, H. R. (2011) Análise econômica do processo de recuperação de um solo sódico no Perímetro Irrigado de Curú - Pentecoste, CE. Revista Brasileira de Engenharia Agrícola e Ambiental, 15 (4) 377-382. https://doi.org/10.1590/S141543662011000400008

Food And Agriculture Organization Of The United Nations. Exame Mundial da Pesca e Aquicultura, 2004.

Food And Agriculture Organization Of The United Nations. Exame Mundial da Pesca e Aquicultura, 2020.

Figueiredo Jr., C. A., \& Valente Jr., A. S. (2008). Cultivo de tilápias no Brasil: Origens e cenário atual. In: XLVI Congresso da Sociedade Brasileira de Economia e Sociologia Rural-SOBER. Brasília (DF): Sociedade Brasileira de Economia e Sociologia Rural.

Freitas, C. O., Rocha, C. T., Loose, C. E., Leite, E. S., \& Silva, J. S. (2015) Gestão de Custo e Viabilidade de Implantação de Piscicultura no Município de Urupá em Rondônia, Amazônia-Brasil. In: Anais do Congresso Brasileiro de Custos-ABC. https://anaiscbc.emnuvens.com.br/anais/article/view/3937

Furlaneto, F. P. B., Esperancini, M. S. T., \& Ayroza, D. M. M. R. (2009) Estudo da viabilidade econômica de projetos de implantação de piscicultura em viveiros escavados. Informações Econômicas, 2 (39), 5-11. http://www.iea.agricultura.sp.gov.br/ftpiea/publicacoes/IE/2009/tec1-0209.pdf

Hoffmann, R., Serrano, O., Neves, E. M., Mendes Thame, A. C., \& Camargo Engler, J. J. (1987) Administração da empresa agrícola. 3 ed. São Paulo: Pioneira. 325p.

Kubitza, F. (2009). Produção de tilápias em tanques de terra: estratégias avançadas no manejo, Panorama. Revista Panorama da Aquicultura,19, 14-21.

Kubitza, F. (2011) Criação de tilápia em sistema com bioflocos sem renovação de água. Revista Panorama da Aquicultura, 21 (125) 14-23.

Leonardo, A. F., Baccarin, A. E., Scorvo Filho, J. D., \& Scorvo, C. M. D. F. (2018) Custo de produção da tilápia do Nilo (Oreochromis niloticus) e do pacu (Piaractus mesopotamicus) no Vale do Ribeira, estado de São Paulo. Informações Econômicas, 48 (1) 21-33. http://www.iea.sp.gov.br/ftpiea/ie/2018/tec21.pdf

Lopes, M. A. \& Carvalho, F. M. (2002) Custo de produção de gado de corte. Boletim técnico n 47. UFLA. Lavras.

Martin, N. B., Serra, R., Oliveira, M. D. M., Ângelo, J. A., \& Okawa, H. (1997) Sistema “CUSTAGRI”: sistema integrado de custos agropecuários. São Paulo: IEA/SAA, 1997, 1-75.

Matsunaga, M., Bemelmans, P. F., \& Toledo, P. (1976) Metodologia de custo utilizada pelo IEA. Agricultura em São Paulo, 23 (1), $123-39$.

Moraes, A. M. (2008) Avaliação zootécnica e econômica do cultivo de tilápia do Nilo, Oreochromis niloticus, em tanques-rede, considerando diferentes rações comerciais. Tese de doutorado - Universidade Federal de Santa Catarina, Florianópolis - SC, p. 51.

Nachiluk, K. \& Oliveira, M. D. M. (2012) Custo de Produção: uma importante ferramenta gerencial na agropecuária. Análises e Indicadores do Agronegócio, 7 (5), 1-7. http://www.iea.sp.gov.br>.

Nogueira, M. P. (2004) Gestão de custos e avaliação de resultados: agricultura e pecuária: Scot Consultoria, 219p.

Nogueira, A. C. (2007) Criação de Tilápias em Tanques-Rede. http://www.sebrae.com.br

Peres, A. A. C., Almeida, G. L., \& Bezerra, V. A. A. (2016) Utilização de técnicas de engenharia econômica na avaliação de empreendimentos e tecnologias. In: Carli, A. A., Santos, F. S., \& Seixas, M. W. A Tecnologia em Prol do Meio Ambiente: a partir de uma análise multidisciplinar. Volta Redonda: Lumen Juris, 292p.

Sabbag, O. J., Rozales, R. R., Tarsitano, M. A. A., \& Silveira, A. N. (2007) Análise econômica da produção de tilápias (Oreochromis niloticus) em um modelo de propriedade associativista em Ilha Solteira/SP. Revista Custos e @ enronegócio on line, 3 (2). http://www.custoseagronegocioonline.com.br/numero2v3/analise\%20economica.pdf

Sandoval Jr, P. (2009) Manual de criação de peixes em tanques-rede. Codevasf, 2009. https://www.codevasf.gov.br/acesso-ainformacao/institucional/biblioteca-geraldo-rocha/publicacoes/publicacoes-editadas-pela-codevasf/manuais/manual-de-criacao-de-peixes-em-tanquesrede_reedicao-2019.pdf

Scorvo Filho, J. D. (2004) O agronegócio da aqüicultura: perspectivas e tendências. São Paulo. http://www.pesca.sp.gov.br/textos_tecnicos.php 
Research, Society and Development, v. 10, n. 2, e38010212502, 2021 (CC BY 4.0) | ISSN 2525-3409 | DOI: http://dx.doi.org/10.33448/rsd-v10i2.12502

Scott, P., Vianna, L. F., \& Mathias, M. A. (2002) Diagnóstico da cadeia aqüícola para o desenvolvimento da atividade no estado do Rio de Janeiro. Panorama da Aqüicultura, 12 (71) 15-25.

Silva, J. R., Rabenschlag, D. R., Feiden, A., Boscolo, W. R., Signor, A. A., \& Bueno, G. W. (2012) Produção de pacu em tanques-rede no reservatório de Itaipu, Brasil: retorno econômico. Archivos de Zootecnia, 63 (234), 245-254. http://dx.doi.org/10.4321/S0004-05922012000200009

Trombeta, T. D., Bueno, G. W. \& Mattos, B. O. (2017) Análise econômica da produção de tilápia em viveiros escavados no Distrito Federal, 2016. Informações Econômicas, 47 (2), 42-49. http://www.iea.sp.gov.br/ftpiea/ie/2017/tec4-0417.pdf

Zimmermann, S. \&. Hasper, T. O. B. 2003. Piscicultura no Brasil: o processo de intensificação da tilapicultura. In: Reunião Anual da Sociedade Brasileira de Zootecnia,Santa Maria. 